\title{
Assessing coral Sr/Ca-SST calibration techniques using the species Diploria strigosa
}

\author{
Yuan-Yuan $\mathrm{Xu}^{1,2}$, Sean Pearson ${ }^{3,4}, \mathrm{~K}$. Halimeda Kilbourne ${ }^{1, *}$
}

*Corresponding author: K. Halimeda Kilbourne, Chesapeake Biological Laboratory, University of Maryland Center for Environmental Science, Solomons, Maryland, USA. (kilbourn@umces.edu)

${ }^{1}$ Chesapeake Biological Laboratory, University of Maryland Center for Environmental Science, Solomons, Maryland, USA.

${ }^{2}$ Now at School of Marine Science and Policy, University of Delaware, Newark, Delaware, USA.

${ }^{3}$ Department of Geology, Gettysburg College, Gettysburg, Pennsylvania, USA

${ }^{4}$ Now at Department of Molecular and Cell Biology, University of Connecticut, Storrs, Connecticut, USA

\begin{abstract}
The coral species Diploria strigosa is a promising archive for paleoclimate reconstruction in the tropical Atlantic, but limited work has been accomplished thus far to quantify the relationship between strontium to calcium ratios and sea surface temperatures in this species. In this study, we collected three modern D. strigosa coral colonies from Anegada, British Virgin Islands to refine the use of this species as a paleoclimate archive. Three regression techniques including ordinary lease squares, reduced major axis, and weighted least squares were used to assess how assumptions implicit in these regression methods influence the calibration. Our analysis demonstrated that regression slopes were strongly impacted by the assumptions about data uncertainty. We recommend using the unbiased weighted least squares regression technique for calibrating the $\mathrm{Sr} / \mathrm{Ca}$ paleothermometer, especially when precise local sea surface
\end{abstract}

(C) 2015. This manuscript version is made available under the Elsevier user license http://www.elsevier.com/open-access/userlicense/1.0/ 
temperature data are unavailable. Combining our $\mathrm{Sr} / \mathrm{Ca}$ data with previously published data from this species results in a mult-site, multi-colony temperature sensitivity of $-0.046( \pm<0.001) \mathrm{mmol} / \mathrm{mol} /{ }^{\circ} \mathrm{C}$ for mean-centered monthly data, $-0.059( \pm 0.001)$ $\mathrm{mmol} / \mathrm{mol} /{ }^{\circ} \mathrm{C}$ for monthly anomalies, and $-0.063( \pm 0.004)$ for annual anomalies. We suggest these relationships are the best available characterization of the temperature dependence of $\mathrm{Sr} / \mathrm{Ca}$ in $D$. strigosa, and can be utilized in future paleoclimate reconstructions.

Keywords: Diploria strigosa; Sr/Ca; Calibration; Weighted least square 


\section{$1 \quad 1$ Introduction}

A few key genera of reef-building corals are used in most paleoclimate studies to

3 reconstruct tropical sea surface temperature (SST) [Corrège, 2006; DeLong et al., 2007;

4 Saenger et al., 2008]. Porites is the genus most often used in the Pacific [e.g., Corrège,

5 2006; Gagan et al., 2012; McGregor and Gagan, 2003; Shen et al., 1996], whereas the

6 Montastraea annularis species complex (now formally assigned to the genus Orbicella,

7 [Budd et al., 2012]) is commonly used in the Atlantic [e.g., Kilbourne et al., 2008;

8 Saenger et al., 2008; Smith et al., 2006; Swart et al., 2002; Watanabe et al., 2001;

$9 \quad$ Watanabe et al., 2002].

10 The genus Diploria is another abundant massive coral genus commonly found

11 growing on Atlantic reefs but it has been used much less extensively for paleoclimate

12 research. Initial work on the genus Diploria primarily focused on slow growing

13 specimens of the species D. labyrinthiformis from Bermuda [Cohen and Thorrold, 2007;

14 Cohen et al., 2004; Draschba et al., 2000; Goodkin et al., 2007; Goodkin et al., 2005;

15 Kuhnert et al., 2002]. The corals used in these studies had annual growth rates in the 2-5

16 mm range and many researchers noted a significant impact of coral growth rates on

17 geochemistry in these slow-growing specimens [Cardinal et al., 2001; Cohen et al., 2004;

18 Goodkin et al., 2007; Goodkin et al., 2005]. Cohen and Thorrold [2007] recommended

19 extremely fine sampling of this species to minimize the impact of biosmoothing [Gagan

20 et al., 2012] and time-transgressive sampling on climate reconstructions. Alternatively,

21 Goodkin et al. [2007] suggested a growth-corrected calibration based on three different 
22 corals. The goal of their study was to provide a universal calibration that could be

23 applied generally to $D$. labyrinthiformis, both modern and fossil specimens.

$24 \quad$ Research on the species D. strigosa is not as well developed as for $D$.

25 labyrinthiformis. Hetzinger et al. [2006] published a 41-year Sr/Ca-SST calibration for a

26 fast growing $D$. strigosa from Guadaloupe, and suggested that $D$. strigosa was a

27 promising archive of Atlantic SST information. They pointed out that faster growth rates

28 in their coral specimen led to less time integration of the sub-samples than with the

29 slower-growing specimens of D. labyrinthiformis examined to date (see [Sadler et al.,

$302014]$ and their figure 4 for an excellent explanation of the relevant skeletal geometry).

31 Three subsequent studies utilized Hetzinger's calibration, citing it as the best available

32 calibration for this species [Giry et al., 2010; Giry et al., 2012; Hetzinger et al., 2010].

33 Giry et al. [2010] investigated the sub-millimeter scale $\mathrm{Sr} / \mathrm{Ca}$ heterogeneity in a specimen

34 of D. strigosa. Their results supported the conclusion by Hetzinger et al. [2006] that time

35 integration of drilled samples is much less in these faster-growing specimens than in the

36 slow-growing D. labyrinthiformis. Additionally, Giry et al. [2010] suggested that micro-

37 milling the thecal wall with a fine $(0.6 \mathrm{~mm})$ drill bit was the best method for extracting a

38 climate signal from this species to avoid skeletal elements with strong non-climatic $\mathrm{Sr} / \mathrm{Ca}$

39 signals.

40 In this study we further refine the use of this species for paleoclimate

41 reconstructions. Hetzinger et al. [2006] defined the Sr/Ca-temperature slope in D.

42 strigosa using a single coral colony, but as Goodkin et al. [2007] pointed out, multi-

43 colony calibrations are inherently more accurate for paleoclimate reconstructions than

44 those that use individual coral specimens selected from a population. In this study, we 
45 explore calibration slopes from multiple modern corals and combine them to provide a

46 more robust $\mathrm{Sr} / \mathrm{Ca}$-SST calibration for this species. We utilize new data from multiple

47 specimens of D. strigosa which grew offshore from the island of Anegada, British Virgin

48 Islands, in the northern Caribbean, and combine it with existing data from specimens

49 which grew offshore from Guadeloupe [Hetzinger et al., 2006] and Bonaire [Giry et al.,

50 2012], to create a regionally applicable calibration slope.

51 Most prior calibration studies used the Ordinary Least Squares (OLS) regression

52 technique, which has been shown to have limitations derived from implicit assumptions

53 about measurement errors [Solow and Huppert, 2004]. In this study, we explore the use

54 of OLS and compare it to other methods that have been recommended as alternates, such

55 as Reduced Major Axis (RMA) regression [Quinn and Sampson, 2002; Nurhati et al.,

56 2009] and Weighted Least Squares (WLS) [DeLong et al., 2007; DeLong et al., 2011;

57 DeLong et al., 2014; Thirumalai et al., 2011]. We compare multiple calibration

58 techniques with the same data to assess how assumptions implicit in different regression

59 methods influence the resulting calibration slopes and we provide our best estimate of the

$60 \mathrm{Sr} / \mathrm{Ca}$-temperature sensitivity for this coral species.

\section{$62 \quad 2$ Data and Methods}

\section{$63 \quad 2.1$ Sampling}

64 The coral samples used in this study were collected as hand samples in March

652013 from the beach berm at Soldier Point, Anegada (Figure 1). Beach berm deposits of

66 coral boulders are common on high-energy coastlines in reef-growing areas and they 
67 provide a near unlimited supply of short (decades-long) coral records from a variety of

68 time periods. We collected pristine-looking coral boulders with the goal of creating a

69 replicated 20th century calibration without any damage to living coral colonies,

70 minimizing the ecological impact of our paleoclimate research.

71 Approximately $5 \mathrm{~cm}$ diameter cores were drilled from each of the three coral

72 boulders in the field. The cores were designated 13AN17, 13AN18, 13AN19 and were

73 cut along the growth direction into approximately $5 \mathrm{~mm}$ thick slabs using a tile saw

74 dedicated to cutting coral cores. Each slab was individually immersed in a clean plastic

75 container with deionized water and ultrasonicated for 30 minutes. Following a rinse in

76 deionized water, the samples were air-dried and stored covered with clean Kimwipes®.

77

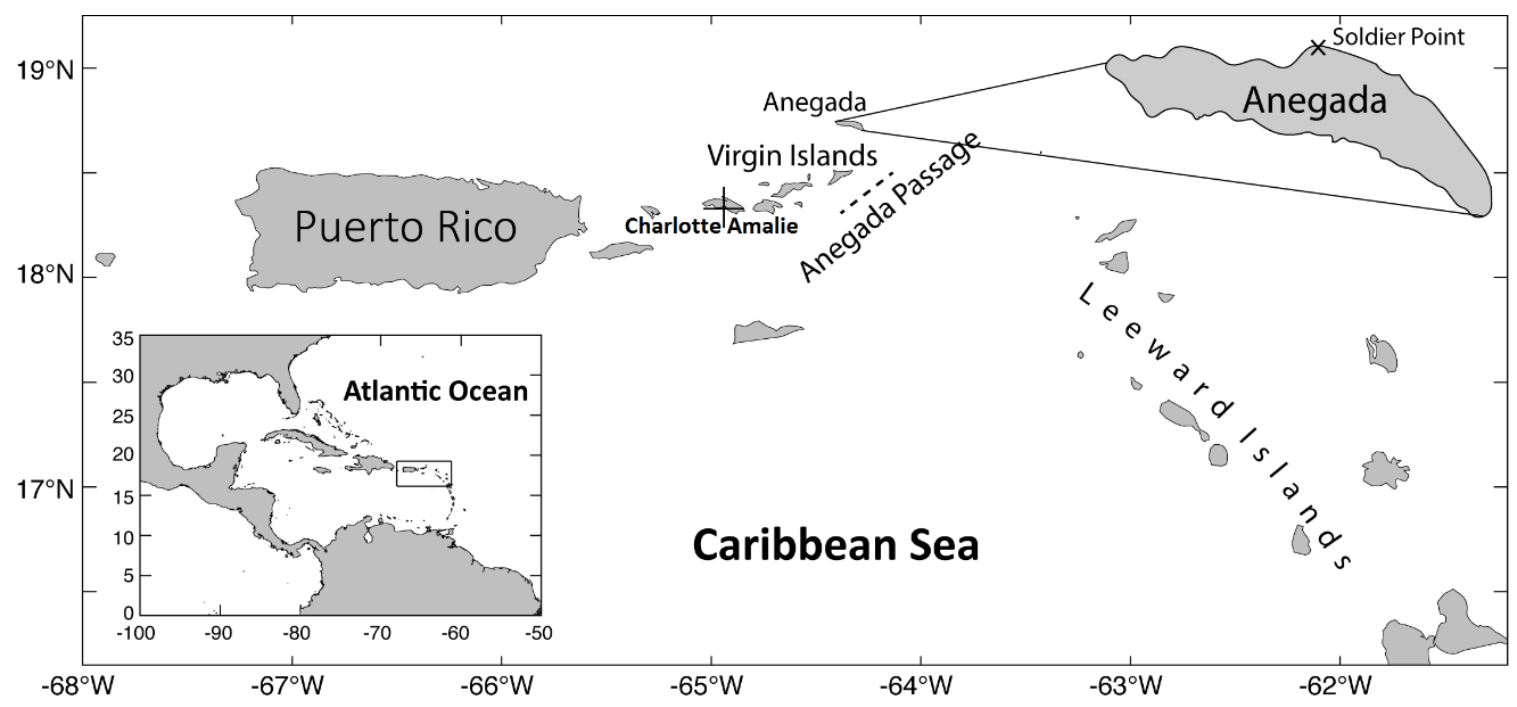

79 Figure 1. Samples for this study were obtained from a beach berm deposit at Soldier Point on

80 the north side of Anegada, British Virgin Islands. This carbonate island lies on the border

81 between the Caribbean Sea and the tropical North Atlantic. Buoy-based SST data discussed in

82 the paper came from Charlotte Amalie harbor on St. Thomas in the U.S. Virgin Islands.

83

84 Coral slabs were drilled using a computer-controlled micromilling system,

85 equipped with a 0.5 -mm diameter carbide steel dental drill bit. Before drilling the coral 
86 slabs, annual extension rates were estimated by measuring the distance between ten

87 density band couplets. The targeted sampling resolution was 12 samples per year. Sub-

88 samples of skeletal powder were extracted carefully at a constant sampling depth of 0.5

$89 \mathrm{~mm}$ per sub-sample along the center of the thecal wall, to obtain the best chronology and

90 environmental signal possible [Giry et al., 2010]. Thin-section billets were cut adjacent

91 to the micro-sampling paths in each core. No evidence of secondary aragonite or calcite

92 were found in the thin sections.

\section{$93 \quad 2.2$ Coral $\mathrm{Sr} / \mathrm{Ca}$}

$94 \mathrm{Sr} / \mathrm{Ca}$ ratios in the coral aragonite were measured using a Perkin Elmer Optima

958300 Inductively Coupled Plasma Optimal Emission Spectrometer (ICP-OES) at the

96 University of Maryland Center for Environmental Science, Chesapeake Biological

97 Laboratory campus. We weighed $150 \pm 50 \mu \mathrm{g}$ coral powder from each sample and

98 dissolved it in different volumes $(2-4 \mathrm{~mL})$ of $2 \%$ trace-metal grade nitric acid to bring

99 the concentration of calcium to $\sim 20 \mathrm{ppm}$. Calibration standards with known calcium and

100 strontium concentrations were used to convert instrumental signal intensity to sample

101 concentration. Reference standards were measured before and after each sample to

102 calculate an instrumental drift correction to be applied to the data, as per Schrag [1999].

103 The calcium and strontium concentrations of the reference standards were similar to the

104 samples, with values of $\sim 20 \mathrm{ppm}$ and $400 \mathrm{ppb}$, respectively. An in-house laboratory

105 coral standard prepared from an Orbicella faveolata coral dissolved in 2\% trace-metal

106 grade nitric acid to similar calcium concentration as the samples provided an independent

107 check of analytical precision and accuracy. The $\mathrm{Sr} / \mathrm{Ca}$ ratios of these two standards were

108 cross calibrated with ICP-OES instruments at the University of Texas at Austin 
109 Analytical Laboratory for Paleoclimate Studies and the US Geological Survey in St.

110 Petersburg, Florida. Long-term analytical precision for the reference standard solution is

$1110.12 \%(2 \sigma, 0.011 \mathrm{mmol}-\mathrm{Sr} / \mathrm{mol}-\mathrm{Ca}, n=4475)$. Long-term analytical precision for the

112 coral standard solution is $0.26 \%(2 \sigma ; 0.023 \mathrm{mmol}-\mathrm{Sr} / \mathrm{mol}-\mathrm{Ca}, n=578)$. These estimates

113 of analytical precision are used to estimate the uncertainty of the Sr/Ca data in our

114 regression analysis. Applying a Sr/Ca-temperature relationship of $0.042 \mathrm{mmol} / \mathrm{mol} /{ }^{\circ} \mathrm{C}$

115 from Hetzinger [2006] to the $2 \sigma$ standard deviations of the reference and coral solutions

116 results in estimated temperature standard errors on individual data points of $0.26^{\circ} \mathrm{C}$ and

$117 \quad 0.55^{\circ} \mathrm{C}$ for reference standard solution and coral standard solution, respectively.

$118 \quad$ 2.3 Coral Chronology

119 In this study, the age of the corals was determined by a combination of uranium-

120 series dates, X-radiographs, and correlations of coral Sr/Ca to SST. Sub-samples

121 weighing on average $600 \pm 200 \mathrm{mg}$ and representing approximately one year of coral

122 growth were cut from coral slabs 13AN17 and 13AN18 for U-series analysis. 13AN19

123 was not subsampled for U-series dating because initially we planned not to use the

124 extremely short core. Uranium-series analysis was undertaken on these sub-samples at

125 the High-Precision Mass Spectrometry and Environment Change Laboratory at National

126 Taiwan University. The wet chemistry was performed following Shen et al. [2003] on

127 the 15th of September, 2013 and instrumental analysis was performed by using

128 Multicollector-Inductively Coupled Plasma-Mass Spectrometry (MC-ICP-MS) following

129 Shen et al. [2012].

130 X-radiographs taken at the United States Geological Survey in St. Petersburg,

131 Florida, were used to reveal the annual density band couplets for age modeling. The 
132 positions of the dated coral pieces were identified on the $\mathrm{X}$-radiographs and an initial

133 depth/age relationship determined by annual density band counting from the position and

134 date indicated.

135 The conversion of the $\mathrm{Sr} / \mathrm{Ca}$ data from depth domain to time domain was

136 achieved by matching coral $\mathrm{Sr} / \mathrm{Ca}$ seasonal cycles to SST seasonal cycles using

137 AnalySeries software (available through NOAA's National Climate Data Center at

138 http://www.ncdc.noaa.gov/data-access/paleoclimatology-data/datasets/software)

139 [Paillard et al., 1996]. The SST record used for alignment is the $2^{\circ} \times 2^{\circ}$ gridded

140 Extended Reconstructed Sea Surface Temperature (ERSST) version 3b data [Smith et al.,

141 2008] centered on $19^{\circ} \mathrm{N}, 64^{\circ} \mathrm{W}$. The time-domain $\mathrm{Sr} / \mathrm{Ca}$ ratios were re-sampled to

142 monthly intervals and provide the primary data used in comparisons with monthly SST

143 time series data. Annual growth rates were calculated from two successive winters in

144 each annual cycle as defined by the depth-domain $\mathrm{Sr} / \mathrm{Ca}$ data.

145 Combining the U-series dates, density banding from the X-rays, and $\mathrm{Sr} / \mathrm{Ca}$

146 seasonal cycles matched to seasonal SST resulted in data organized in relative time but

147 lacking a firm date because of the uncertainty in the U-series dates for each sample. We

148 correlated the $\mathrm{Sr} / \mathrm{Ca}$ anomalies to lagged SST anomalies over a range of time lags around

149 the U-series uncertainty to further narrow the age of the samples. Note that we compared

$150 \mathrm{Sr} / \mathrm{Ca}$ measured in coral 13AN19 with the values measured in coral 13AN17 to determine

151 the age of 13AN19 because their stratigraphic position and degree of surface weathering

152 (none) in the field indicated that they likely washed ashore in the same storm. The

153 strongest correlation in a lagged correlation analysis of coral 13AN19 Sr/Ca and SST

154 over a wide range of time confirmed the age of 13AN19. 
157 (NOAA/NCDC) ERSST v.3b [Smith et al., 2008] is the major temperature data source we

158 used for the Sr/Ca-SST calibrations. The temporally and spatially complete ERSST data

159 were created by interpolating between gaps in the instrumental database [Smith and

160 Reynolds, 2004] and in many locations gridded data products like this one are the only

161 data available for comparing with modern coral geochemical data. Gridded data products

162 like ERSST do not always capture fine-scale temperature variations that a coral may

163 experience at the local level, so we also compared the gridded data with both a higher

164 resolution $\left(0.25^{\circ} \times 0.25^{\circ}\right)$ satellite-derived Optimum Interpolation SST (OISST v.2)

165 [Reynolds et al., 2007] and NOAA National Data Buoy Center SST measurements from

166 Charlotte Amalie, US Virgin Islands, about 75km from Soldier Point, Anegada (Figure

167 1). The ERSST and OISST data over 1981-2012 are highly correlated on monthly scales

$168(r=0.98, p<0.01, n=376)$. Note that the variances of the ERSST and OISST data are

1691.18 and 1.13 , respectively. The average absolute difference between the records is

$170 \quad 0.27^{\circ} \mathrm{C}$. The available buoy data (from $2005-2012$ ) are also highly correlated with

171 ERSST data on monthly scales $(r=0.85, p<0.01, n=73)$. The variance of available

172 buoy data is 1.89 , which is higher than the variances of large-scale gridded data. The

173 average absolute difference between buoy data and ERSST data is $1.45^{\circ} \mathrm{C}$, which is also

174 much higher than the difference between OISST and ERSST data.

$175 \quad 2.5$ Statistical Methods

176 The salient features of the two regression techniques most commonly used in

177 coral-paleoclimate work, OLS and RMA are compared in the following paragraphs, with 
178 a subsequent description of WLS and a bootstrapping procedure we developed for this

179 study to estimate the uncertainty of our calibrations.

180 OLS is a generalized linear modeling technique that regresses a response variable

181 on a predictor variable [Cavalli-Sforza and Edwards, 1967]. This technique minimizes

182 the sum of squared vertical distances between the observed response variables and the

183 predicted variables [Cavalli-Sforza and Edwards, 1967]. RMA is also a least-squares

184 method but differs from OLS in that it uses a different definition for the residuals. It

185 accounts for potential errors in both variables simultaneously by minimizing the distance

186 perpendicular to the regression line [Clarke, 1980].

187 The primary difference between OLS and RMA is that RMA assumes equal error

188 variances exist in both the dependent variable and the independent variable, while OLS

189 only accounts for errors in the dependent variable [Smith, 2009]. The resulting difference

190 in regression lines is that OLS regression lines are asymmetric, i.e., dependent on which

191 variable is on the $\mathrm{x}$-axis. However, the RMA regression lines are symmetric with respect

192 to inversion of the axes. It has been pointed out that OLS regressions for paleoclimate

193 reconstructions produce a biased estimate of SST due to the presence of errors in SST

194 used in the calibration [Delong et al., 2007; Solow and Huppert, 2004]. Solow and

195 Huppert [2004] recommended a bias correction and Delong et al. [2007] recommended

196 Maximum Likelihood Estimation regression technique instead, but to the best of our

197 knowledge, few studies have yet incorporated these recommendations.

$198 \quad$ Fitch and Margoliash [1967] suggested the Weighted Least Squares (WLS)

199 method to account for uncertainty in both independent and dependent variables for

200 regressions in general. In this technique, each term includes an additional weight 
201 determining how much each observation in the data set influences the final parameter

202 estimates. The weights for each point are assigned by the reciprocal of the estimated

203 uncertainty in both variables, $\mathrm{Sr} / \mathrm{Ca}$ and SST in this case. Less weight is given to the less

204 precise measurements and more weight to more precise measurements.

205 WLS has been suggested as a more robust alternative to OLS in situations where

206 there is the potential for error in both regression variables and for correlated errors in

207 both regression variables [York et al., 2004]. WLS minimizes the weighted sum-of-

208 squares, accounting for estimated errors and covariance in both dependent and

209 independent variables [Fitch and Margoliash, 1967]. York et al. [2004] put forth a

210 method for calculating the standard errors on the slope and intercept for WLS regression

211 that makes the method exactly equal to Maximum Likelihood Estimation regression

212 favored by the statistics community. The slope, intercept, and standard errors of

213 regressions in this study were calculated following [York et al., 2004] using the

214 MATLAB code provided in [Thirumalai et al., 2011].

215 We used the 2-sigma percent analytical precision of our coral standard $(0.26 \%)$

216 multiplied by each $\mathrm{Sr} / \mathrm{Ca}$ determination to estimate $\mathrm{Sr} / \mathrm{Ca}$ uncertainty. The SST

217 uncertainty estimates provided with the ERSST v3b data served for estimating the SST

218 uncertainty.

219 Additionally, we developed a bootstrap method with weighted least squares

220 (BWLS) to iteratively determine the range of calibrations possible from a given dataset.

221 In our BWLS technique, $75 \%$ of the data were randomly selected 1000 times and each

222 selection was analyzed using the WLS technique [York et al., 2004]. Each random

223 selection leaves out $25 \%$ of the data that can be used to evaluate the calibration. In 
224 contrast to the errors for OLS, RMA, and WLS, which are calculated from a single

225 calibration, the BWLS calibration technique uses the 1000 WLS regression slopes to

226 estimate the $95 \%$ confidence interval on the value of the regression slope according to

227 equation 2.4 in Efron and Tibshirani [1986].

228 The BWLS technique determines the range of regression lines that can be

229 obtained from the regression data and allows us to estimate how results may differ if we

230 were to do the calibration multiple times with data that have the same underlying $\mathrm{Sr} / \mathrm{Ca}$ -

231 SST relationship and error structure. It results in an estimate of the uncertainty in the

232 regression slope that is based on the actual data, compared with standard methods that

233 make assumptions about the data distribution and error structure.

234 A complicating factor for multi-colony calibrations is that differences in mean

$235 \mathrm{Sr} / \mathrm{Ca}$ values have been found in some Diploria strigosa corals growing on the same reef

236 at the same time that seem unrelated to temperature [Giry et al., 2012]. This study uses

237 two approaches to compensate for potential mean shifts with $\mathrm{Sr} / \mathrm{Ca}$ data from three

238 colonies. The approaches are to (1) center the data before regression by removing the

239 mean Sr/Ca value of each coral colony and removing the mean SST value, and (2) regress

240 using the $\mathrm{Sr} / \mathrm{Ca}$ and SST anomalies i.e., remove the average annual cycle in $\mathrm{Sr} / \mathrm{Ca}$ and

241 SST time series.

242

2433 Results

$244 \quad 3.1$ Age Model

245 Corals 13AN17, 13AN18, and 13AN19 grew 18, 28, and 10 years with extension

246 rates ( \pm standard error) of $6.9( \pm 0.4) \mathrm{mm} / \mathrm{yr}, 5.6( \pm 0.2) \mathrm{mm} / \mathrm{yr}$, and $6.2( \pm 0.4) \mathrm{mm} / \mathrm{yr}$ 
247 respectively, reflected in the regular annual density bands visible in the X-radiographs of

248 the coral slabs (Figure 2). Uranium-series dates for corals 13AN17 and 13AN18 (Table 1)

249 are $1989.5 \pm 0.58 \mathrm{CE}$ and $1953.3 \pm 0.72 \mathrm{CE}$, respectively. Correlating the $\mathrm{Sr} / \mathrm{Ca}$

250 anomalies to SST anomalies over a range of time lags around the U-series uncertainty

251 leads us to conclude that the cores 13AN17 and 13AN18 represent coral growth from

252 1990-2008 and 1948-1977 respectively. The minimum lagged correlation of 13AN19

253 Sr/Ca to instrumental SST over the $20^{\text {th }}$ century led us to assign an age range of 1997-

2542008 to this coral.

255

256 Table 1. U-Th isotopic compositions and ${ }^{230}$ Th ages for subsamples of coral slabs, 13AN17 and 257 13AN18, collected from Anegada, British Virgin Islands.

\begin{tabular}{|c|c|c|c|c|c|c|c|c|c|}
\hline $\begin{array}{l}\text { Sample } \\
\text { ID }\end{array}$ & $\begin{array}{c}\text { Weight } \\
\text { (g) }\end{array}$ & $\begin{array}{l}{ }^{238} \mathrm{U} \\
\text { (ppb) }\end{array}$ & $\begin{array}{l}{ }^{232} \mathrm{Th} \\
\text { (ppt) }\end{array}$ & $\begin{array}{c}\delta^{234} \mathrm{U} \\
\text { Measured }\end{array}$ & $\begin{array}{c}{ }^{\left[{ }^{230} \mathrm{Th} /{ }^{238} \mathrm{U}\right]} \\
\text { Activity }{ }^{c}\end{array}$ & $\begin{array}{c}{ }^{\left[{ }^{230} \mathrm{Th} /{ }^{232} \mathrm{Th}\right]} \\
\mathrm{ppm}^{d}\end{array}$ & $\begin{array}{c}\text { Age } \\
\text { Uncorrected }\end{array}$ & $\begin{array}{c}\text { Age } \\
\text { Corrected }^{c, e}\end{array}$ & $\begin{array}{l}\delta^{234} \mathrm{Uinitia} \\
\text { Corrected }^{b}\end{array}$ \\
\hline $13 \mathrm{AN} 17$ & 0.1794 & $1914.1 \pm 2.0$ & $34.3 \pm 2.6$ & $148.9 \pm 1.7$ & $0.000254 \pm 0.000006$ & $234 \pm 18$ & $24.12 \pm 0.54$ & $23.71 \pm 0.58$ & $148.9 \pm 1.7$ \\
\hline $13 \mathrm{AN} 18$ & 0.1938 & $2041.1 \pm 2.2$ & $27.6 \pm 2.4$ & $147.4 \pm 1.7$ & $0.000634 \pm 0.000007$ & $775 \pm 68$ & $60.31 \pm 0.70$ & $59.99 \pm 0.72$ & $147.4 \pm 1.7$ \\
\hline
\end{tabular}

${ }^{a} \delta^{234} \mathrm{U}=\left(\left[{ }^{234} \mathrm{U} /{ }^{238} \mathrm{U}\right]_{\text {activity }}-1\right) \times 1000$

${ }^{b} \delta^{234} \mathrm{U}_{\text {initial }}$ corrected was calculated based on ${ }^{230} \mathrm{Th}$ age $(\mathrm{T})$, i.e., $\delta^{234} \mathrm{U}_{\text {initial }}=\delta^{234} \mathrm{U}_{\text {measured }} X \mathrm{e}^{\lambda 234^{* T} \mathrm{~T}}$, and $\mathrm{T}$ is corrected age.

${ }^{c}\left[{ }^{230} \mathrm{Th} /{ }^{238} \mathrm{U}\right]_{\text {activity }}=1-\mathrm{e}^{-\lambda 230 T}+\left(\delta^{234} \mathrm{U}_{\text {measured }} / 1000\right)\left[\lambda_{230} /\left(\lambda_{230}-\lambda_{234}\right)\right]\left(1-\mathrm{e}^{-(\lambda 230-\lambda 234) T}\right)$, where $T$ is the age.

${ }^{d}$ The degree of detrital ${ }^{230} \mathrm{Th}$ contamination is indicated by the $\left[{ }^{230} \mathrm{Th} /{ }^{232} \mathrm{Th}\right]$ atomic ratio instead of the activity ratio.

${ }^{e}$ Age corrections for samples were calculated using an estimated atomic ${ }^{230} \mathrm{Th} /{ }^{232} \mathrm{Th}$ ratio of $4 \pm 2 \mathrm{ppm}$ [Shen et al., 2008]. 


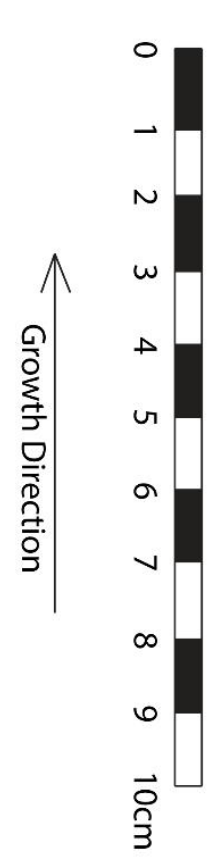

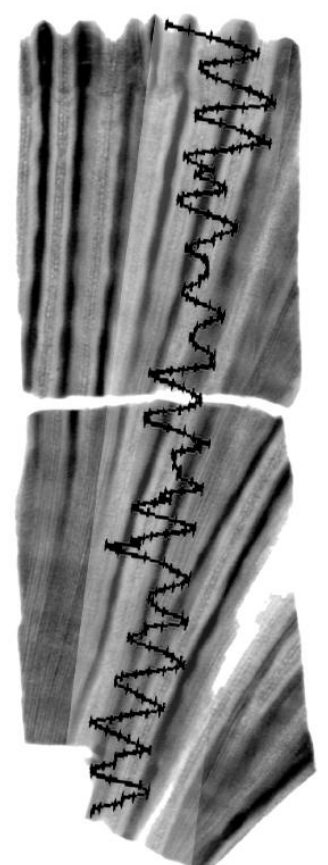

13AN17
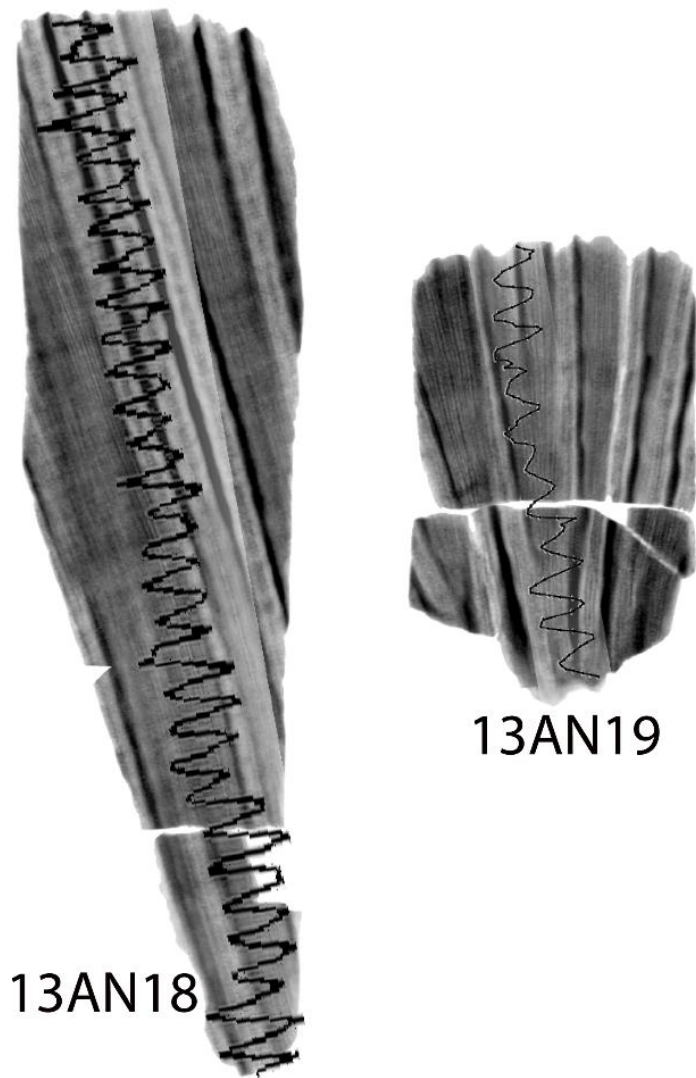

13AN19
259

260

261

262

263

264

265

266

267

Figure 2. X-radiographs of the corals used in this study. Raw Sr/Ca-depth plots are displayed on the X-radiographs with high $\mathrm{Sr} / \mathrm{Ca}$ values towards the left.

\subsection{Coral Strontium-Calcium Ratios}

The monthly Sr/Ca ratios displayed strong seasonal variation (Figure 3). The mean and standard deviation of the coral skeletal $\mathrm{Sr} / \mathrm{Ca}$ in the three cores 13AN17, 13AN18, and 13AN19 were $8.99 \pm 0.06 \mathrm{mmol} / \mathrm{mol}, 9.13 \pm 0.06 \mathrm{mmol} / \mathrm{mol}$, and $8.95 \pm$ $0.06 \mathrm{mmol} / \mathrm{mol}$, respectively. The standard deviation of each time series is controlled by the range of the seasonal cycle and can be thought of as a measure of the seasonal $\mathrm{Sr} / \mathrm{Ca}$ range in each coral. Periods of maximum $\mathrm{Sr} / \mathrm{Ca}$ ratios correspond to low-density bands

270 and minimum $\mathrm{Sr} / \mathrm{Ca}$ ratios correspond to high-density bands, consistent with high-density

271 bands forming in the warm boreal summer and low-density bands forming during the 
272 relatively cool winter as found in Orbicella faveolata at this latitude [Watanabe et al.,

273 2002, Kilbourne et al., 2008]. Standards run with the samples show no similar offsets

274 indicating the mean differences between corals are not an analytical artifact, but represent

275 true population-scale variations in mean skeletal $\mathrm{Sr} / \mathrm{Ca}$.

276
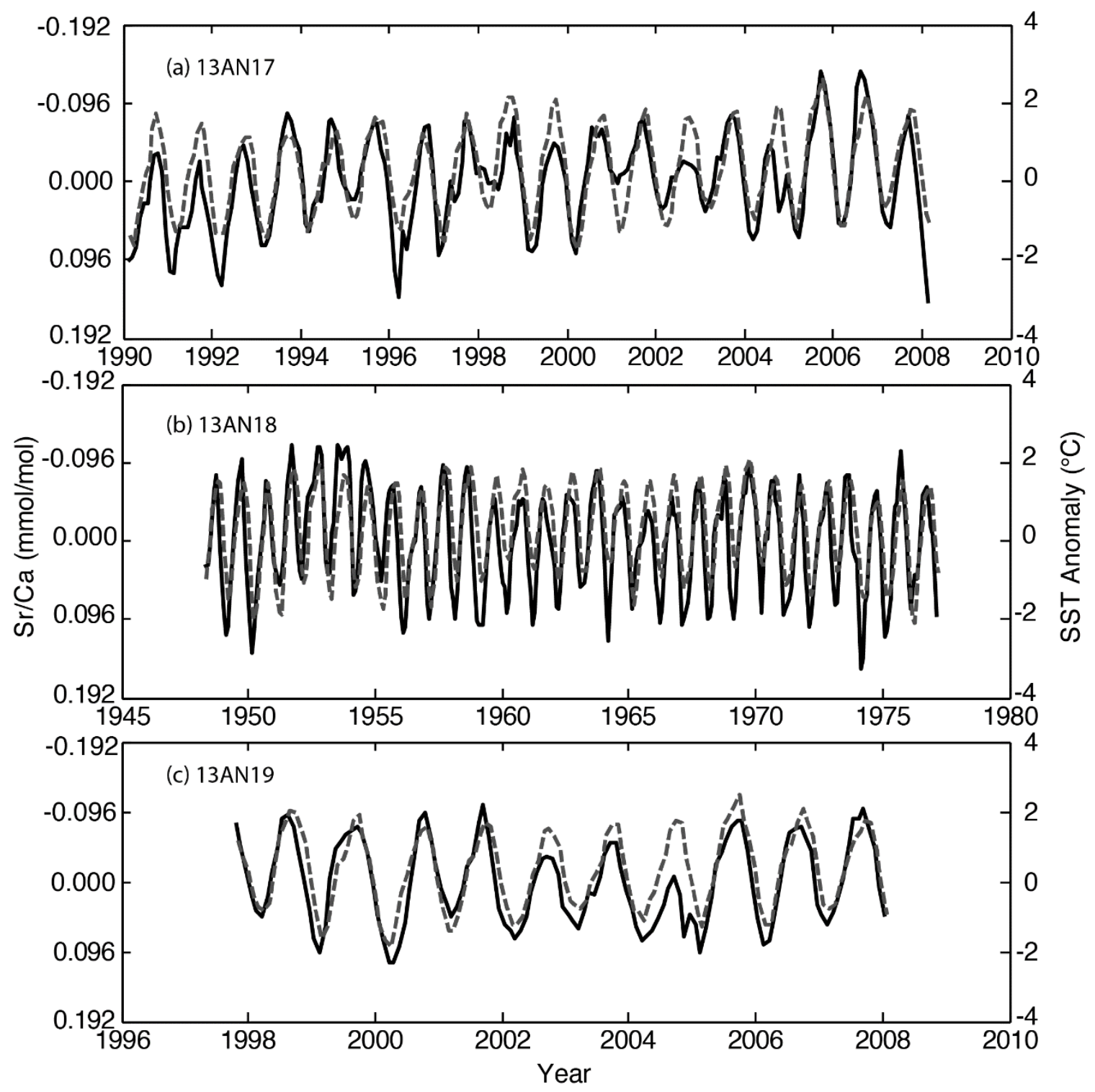

278 Figure 3. Reconstructed SST anomalies from modern corals by using mean-centered $\mathrm{Sr} / \mathrm{Ca}$

279 records. From top to bottom the panels represent coral 13AN17, 13AN18, and 13AN19, 
respectively. Solid lines represent the Sr/Ca (left axis) and Sr/Ca-based SST anomalies (right

281 axis). Dashed lines represent the gridded SST. Coral Sr/Ca-derived SST anomaly was calculated

282 using the OLS regression slope of $-0.048 \mathrm{mmol} / \mathrm{mol} /{ }^{\circ} \mathrm{C}$ from this study.

\subsection{Calibration of $\mathrm{Sr} / \mathrm{Ca}$ with SST}

First we report the results of the mean-centered data regressions. Within a colony,

286 the three least squares regression techniques, OLS, WLS and BWLS, produced similar

$287 \mathrm{Sr} / \mathrm{Ca}$-SST regression slopes, but the slope of the RMA regression in each coral colony is

288 different from the $\mathrm{Sr} / \mathrm{Ca}-\mathrm{SST}$ regression slopes determined with the other regression

289 techniques (Table 2). The regression slopes differ slightly between colonies no matter

290 what regression technique is applied (Table 2). Similar to the results for the individual

291 corals, when the data from all three corals are centered and combined, the ordinary least

292 squares and weighted least squares methods give similar results, but the RMA regression

293 is significantly different (Table 2, Figure 4).

We repeat these four different calibration techniques with $0.3^{\circ} \mathrm{C}, 0.5^{\circ} \mathrm{C}$ and $1.0^{\circ} \mathrm{C}$

295 estimated errors on all the temperature measurements to demonstrate the sensitivity of the

296 calculated slopes to the ratio of uncertainty in the regression variables. The results show

297 that the BWLS slope is closer to that obtained by OLS when the temperature uncertainty

298 is small (average SST uncertainty $0.15^{\circ} \mathrm{C}$, Figure $4 \mathrm{a}$ ), consistent with the OLS

299 assumption of zero error in the $\mathrm{x}$-axis variable. The BWLS slope is similar to that

300 obtained by RMA when the temperature uncertainty is about $\sim 0.5^{\circ} \mathrm{C}$, consistent with the

301 estimated uncertainty of our $\mathrm{Sr} / \mathrm{Ca}$ data $\left(0.023 \mathrm{mmol} / \mathrm{mol}\right.$ or $\left.\sim 0.5^{\circ} \mathrm{C}\right)$ and the RMA

302 assumption of equal error in $\mathrm{x}$ and $\mathrm{y}$ variables. The BWLS becomes steeper as the

303 estimated temperature uncertainty increases (Figure $4 \mathrm{~b}$ and c), indicative of the increased 
304 relative uncertainty in the $\mathrm{x}$-axis variable. Flipping the regression so that the dependent

305 regressor is $\mathrm{Sr} / \mathrm{Ca}$ instead of SST would result in effectively the same relationships

306 between RMA and WLS because neither method is sensitive to the choice of dependent

307 variable. However, OLS would plot as a mirror image of the current line across the RMA

308 axis in Figure 4.

309 Table 2. Summary of Sr/Ca-SST relationships between the mean-centered Sr/Ca time series and 310 ERSST data in three modern corals. Units on the regression slopes are $\mathrm{mmol} / \mathrm{mol} /{ }^{\circ} \mathrm{C}$. The 311 regression equation for the BWLS technique represents the average of all bootstrap regressions.

\begin{tabular}{lllll}
\hline $\begin{array}{l}\text { Regression } \\
\text { Method }\end{array}$ & 13AN17 & 13AN18 & 13AN19 & All corals \\
\hline OLS & $-0.043 \pm 0.003$ & $-0.052 \pm 0.002$ & $-0.047 \pm 0.002$ & $-0.048 \pm 0.001$ \\
RMA & $-0.053 \pm 0.002$ & $-0.059 \pm 0.002$ & $-0.053 \pm 0.002$ & $-0.056 \pm 0.001$ \\
WLS & $-0.046 \pm 0.002$ & $-0.054 \pm 0.001$ & $-0.048 \pm 0.002$ & $-0.050 \pm 0.001$ \\
BWLS & $-0.046 \pm 0.001$ & $-0.054 \pm 0.001$ & $-0.048 \pm 0.001$ & $-0.050 \pm 0.001$ \\
\hline
\end{tabular}




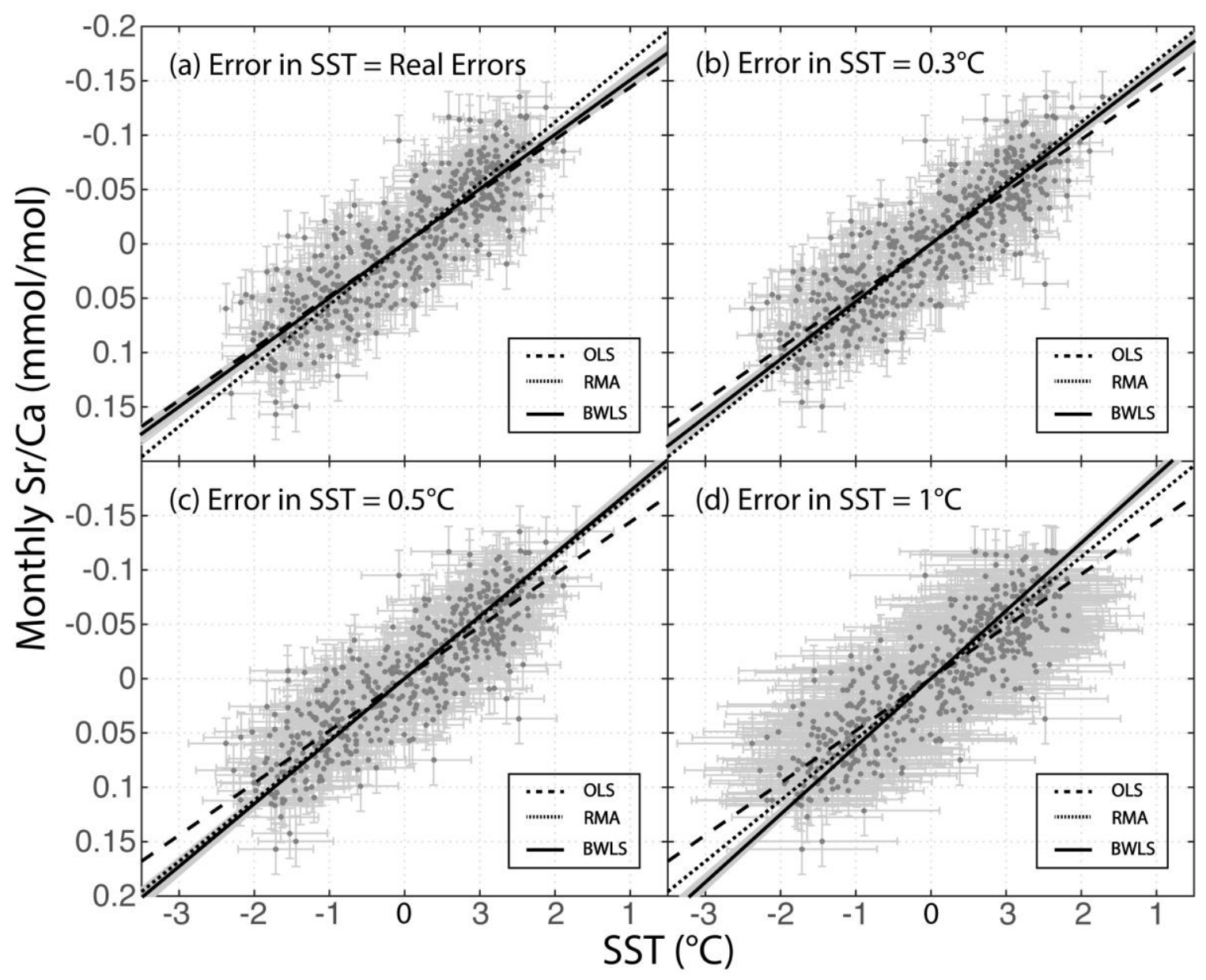

321 Figure 4. Regression lines determined by applying OLS, RMA, and WLS techniques to mean322 centered $\mathrm{Sr} / \mathrm{Ca}$ and mean-centered ERSSTs. Estimated errors in SST come from NOAA/NCDC 323 ERSSTV.3b dataset [Smith et al., 2008]. The grey points with error bars (2SE) represent data 324 points in all three coral cores from Anegada.

A weakness of calibrating monthly mean-centered Sr/Ca data to SST is that the

327 regression results are strongly controlled by the seasonal cycle [Crowley et al., 1999;

328 DeLong et al., 2007] and may be influenced by sub-annual skeletal thickening [Gagan et

$329 a l ., 2012]$. To get around this issue, we repeated the regression analysis on the Sr/Ca and

330 SST monthly anomalies. The correlation between Sr/Ca anomalies and SST anomalies

331 are not significant at the $95 \%$ confidence level in all three modern corals, though the 
332 correlation becomes significant when the data from all three corals are combined (Table $3333)$.

334 The anomaly data produced a wide range of $\mathrm{Sr} / \mathrm{Ca}$-SST relationships, between

$3350.25 \mathrm{mmol} / \mathrm{mol} /{ }^{\circ} \mathrm{C}$ and $0.89 \mathrm{mmol} / \mathrm{mol} /{ }^{\circ} \mathrm{C}$. Unlike the results obtained using the mean-

336 centered data, regression analysis with anomaly data produced Sr/Ca-SST slopes that are

337 statistically different depending on regression technique (Table 4, Figure 5). Only the

338 WLS and related BWLS results were the same. Similar to the set of regressions on

339 mean-centered data, the slopes of the RMA regressions are higher than the slopes of the

340 other regressions. The large difference in regression equations shows the importance of

341 assumptions about the distribution of error in the data when the signal-to-noise ratio is

342 small as is the case with the monthly anomaly data.

343 We also repeat these four different calibration techniques on the combined three-

344 coral dataset with $0.2,0.25$, and $0.3^{\circ} \mathrm{C}$ errors on the temperature measurements to

345 demonstrate the sensitivity of the slope to statistical method and temperature uncertainty

346 when using Sr/Ca and SST anomalies. The results are similar to the parallel experiment

347 on the mean-centered data with the average BWLS slope increasing with increasing

348 uncertainty in temperature measurements (Figure 5). However with the lower signal to

349 noise ratio in the anomaly data, the calculated slopes are much more sensitive to the

350 temperature uncertainty. The BWLS regression shows more variance with larger SST

351 errors. As with the mean-centered regressions, the BWLS slope is more similar to that

352 obtained with OLS when the temperature uncertainty is small (Figure 5a and b).

353 Increasing the temperature uncertainty to only 0.25 increases the BWLS slope to a value

354 similar to that obtained by RMA (Figure 5c). When the errors in temperature are larger 
355 than $0.25^{\circ} \mathrm{C}$, the BWLS method estimates a much steeper slope than either of the other

356 methods (Figure 5d).

357 Table 3. Correlation coefficients between $\mathrm{Sr} / \mathrm{Ca}$ anomalies and ERSST temperature anomalies in 358 modern corals at this site.

\begin{tabular}{lllll}
\hline \multirow{2}{*}{ Correlation coefficients (r) } & AN17 & AN18 & AN19 & All \\
p-value & -0.44 & -0.30 & -0.53 & -0.38 \\
Number of data points (N) & $>0.05$ & $>0.05$ & $>0.05$ & $<0.05$ \\
\hline
\end{tabular}

359

360

Table 4. Summary of Sr/Ca-SST relationships between the Sr/Ca and ERSST monthly anomaly 362 data in three modern corals. Units on the regression slopes are $\mathrm{mmol} / \mathrm{mol} /{ }^{\circ} \mathrm{C}$. The regression equation for the BWLS technique represents the average of all bootstrap regressions.

\begin{tabular}{lllll}
\hline $\begin{array}{l}\text { Regression } \\
\text { Method }\end{array}$ & 13AN17 & 13AN18 & 13AN19 & All corals \\
\hline OLS & $-0.043 \pm 0.006$ & $-0.025 \pm 0.004$ & $-0.047 \pm 0.007$ & $-0.034 \pm 0.003$ \\
RMA & $-0.098 \pm 0.006$ & $-0.081 \pm 0.004$ & $-0.053 \pm 0.007$ & $-0.089 \pm 0.003$ \\
WLS & $-0.069 \pm 0.006$ & $-0.043 \pm 0.004$ & $-0.067 \pm 0.007$ & $-0.056 \pm 0.003$ \\
BWLS & $-0.069 \pm 0.004$ & $-0.043 \pm 0.003$ & $-0.067 \pm 0.005$ & $-0.056 \pm 0.002$ \\
\hline
\end{tabular}




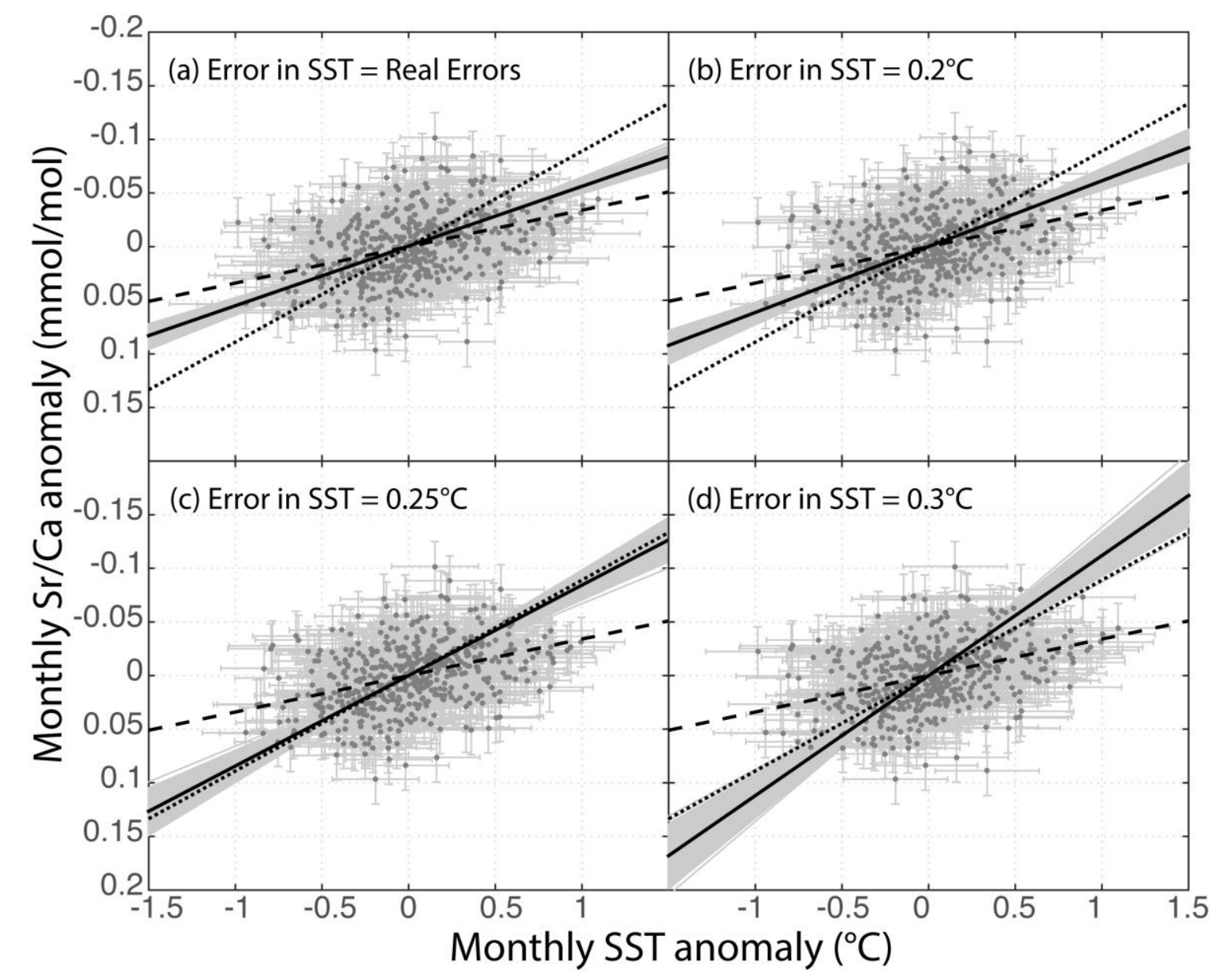

368 Figure 5. Regression lines determined by applying OLS, RMA, and BWLS techniques to Sr/Ca 369 anomalies and ERSST anomalies. The black points with error bars (2SE) represent data points in 370 all three coral cores from Anegada.

Another method to remove the influence of the seasonal cycle is to calibrate with

373 centered mean annual data. Different from the monthly anomaly data, the correlation

374 between annual mean $\mathrm{Sr} / \mathrm{Ca}$ and SST anomalies are significant at the $95 \%$ confidence

375 level in $13 \mathrm{AN} 17,13 \mathrm{AN} 18$ and the combined data from all three corals, though the

376 correlation becomes insignificant in coral 13AN19 (Table 5), likely because of the short

377 length of the core. A plot of the data (Figure 6) shows much higher signal to noise ratio

378 compared to the anomaly data regression analysis. However, the calculated regression

379 slopes (Table 6) have larger error bars because of the reduced number of data points. 
380 Notably the BWLS regression using annual data with all of the corals from Anegada (-

$3810.052 \pm 0.006 \mathrm{mmol} / \mathrm{mol} /{ }^{\circ} \mathrm{C}$ ) is nearly identical to the slope calculated with seasonal data

$382\left(-0.050 \pm 0.001 \mathrm{mmol} / \mathrm{mol} /{ }^{\circ} \mathrm{C}\right)$.

383 Table 5. Correlation coefficients between annual mean Sr/Ca anomalies and ERSST

384 temperature anomalies in modern corals at this site.

\begin{tabular}{lllll}
\hline \multirow{2}{*}{ Correlation coefficients (r) } & AN17 & AN18 & AN19 & All \\
p-value & -0.70 & -0.38 & -0.53 & -0.51 \\
Number of data points (N) & $<0.05$ & $<0.05$ & $>0.05$ & $<0.05$ \\
& 17 & 28 & 10 & 55 \\
\hline
\end{tabular}

385

386 Table 6. Summary of Sr/Ca-SST relationships between the $\mathrm{Sr} / \mathrm{Ca}$ and ERSST annual anomaly data 387 in three modern corals. Units on the regression slopes are $\mathrm{mmol} / \mathrm{mol} /{ }^{\circ} \mathrm{C}$. The regression

388 equation for the BWLS technique represents the average of all bootstrap regressions.

\begin{tabular}{lllll}
$\begin{array}{l}\text { Regression } \\
\text { Method }\end{array}$ & 13AN17 & 13AN18 & 13AN19 & All corals \\
\hline OLS & $-0.062 \pm 0.017$ & $-0.028 \pm 0.013$ & $-0.047 \pm 0.027$ & $-0.041 \pm 0.010$ \\
RMA & $-0.090 \pm 0.016$ & $-0.074 \pm 0.013$ & $-0.089 \pm 0.024$ & $-0.081 \pm 0.009$ \\
WLS & $-0.070 \pm 0.023$ & $-0.039 \pm 0.017$ & $-0.050 \pm 0.033$ & $-0.052 \pm 0.013$ \\
BWLS & $-0.070 \pm 0.010$ & $-0.040 \pm 0.009$ & $-0.051 \pm 0.010$ & $-0.052 \pm 0.006$ \\
\hline
\end{tabular}

389 


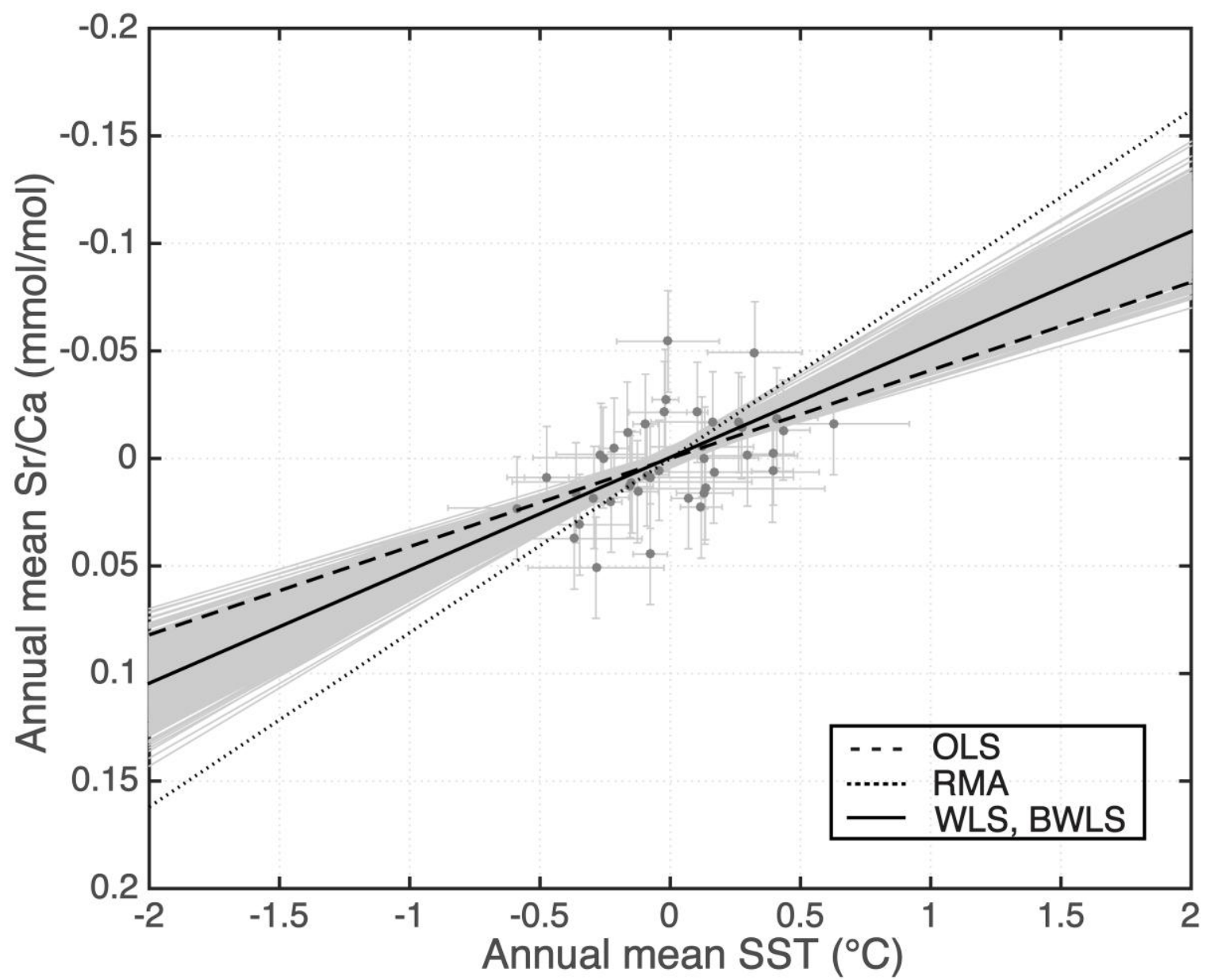

Figure 6. Regression lines determined by applying OLS, RMA, WLS, and BWLS technique to annual mean $\mathrm{Sr} / \mathrm{Ca}$ and ERSST data.

393

394

We combined the data collected from Anegada with existing data from

396 Guadeloupe [Hetzinger et al., 2006] and Bonaire [Giry et al., 2012] to create a bulk

397 calibration slope for $D$. strigosa in Caribbean. The resulting slope from the multi-site

398 calibration using the BWLS technique was $-0.046(\mathrm{SE}<0.001) \mathrm{mmol} / \mathrm{mol} /{ }^{\circ} \mathrm{C}$ for mean-

399 centered data (Figure 7$),-0.059( \pm 0.001) \mathrm{mmol} / \mathrm{mol} /{ }^{\circ} \mathrm{C}$ for monthly anomalies (Figure 8 ),

400 and $-0.063( \pm 0.004)$ for annual anomalies (Figure 9). 


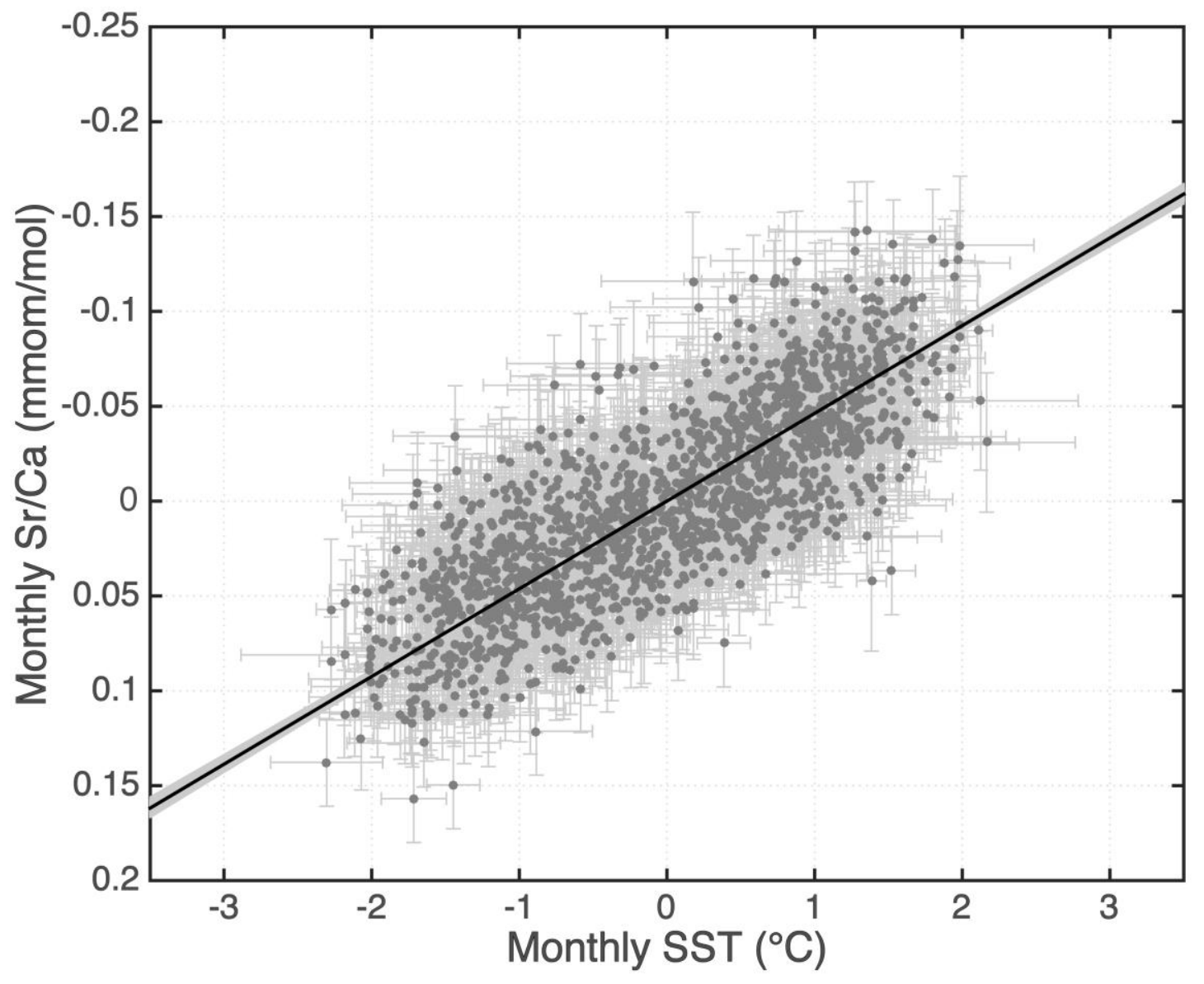

401

402 Figure 7. Regression lines determined by applying the BWLS technique to mean-centered Sr/Ca 403 and mean-centered ERSST data from multiple sites including Anegada, Guadeloupe, and Bonaire. 404 405 


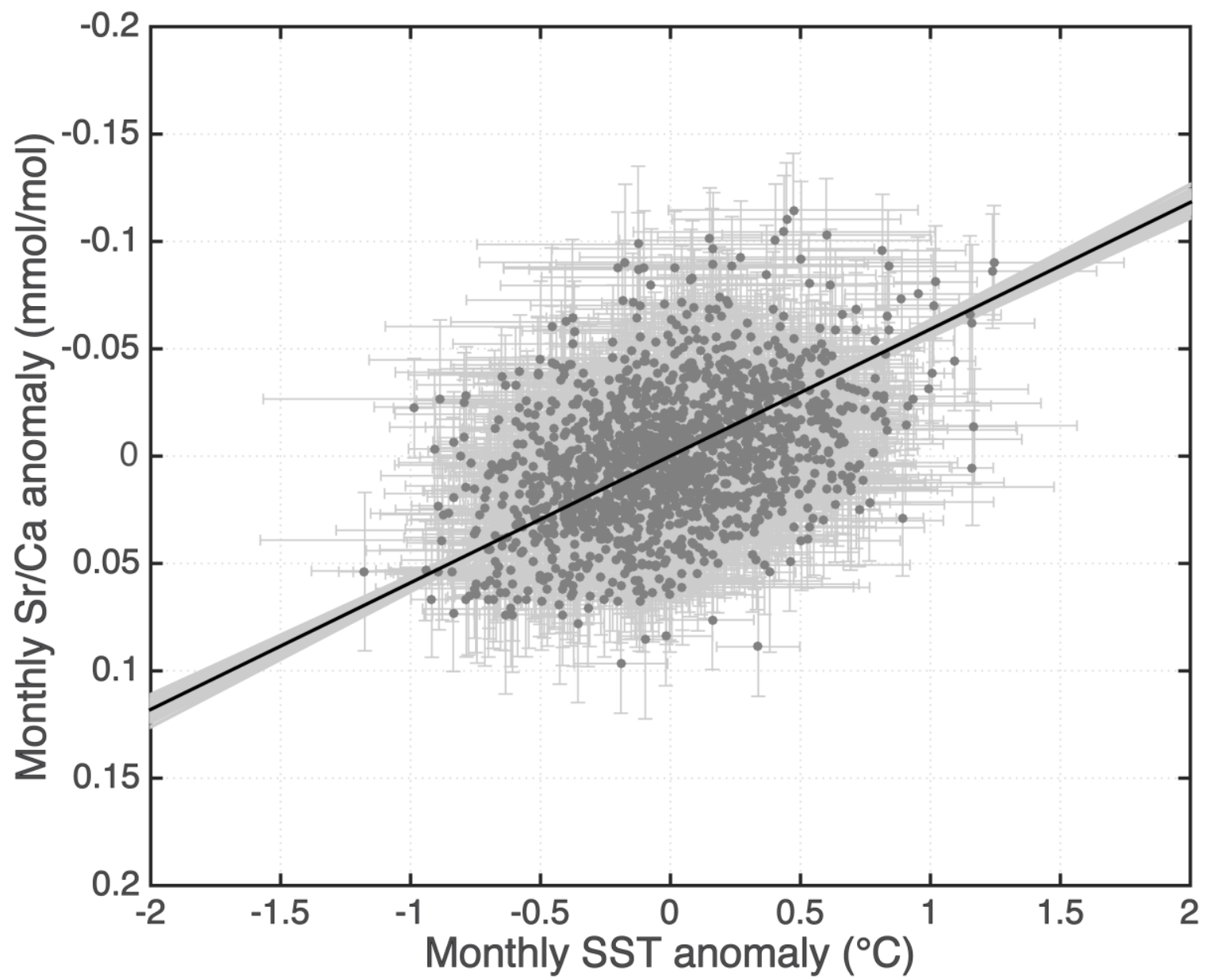

Figure 8. Regression lines determined by applying the BWLS technique to $\mathrm{Sr} / \mathrm{Ca}$ anomalies and 409 ERSST anomalies from Anegada, Guadeloupe, and Bonaire. 


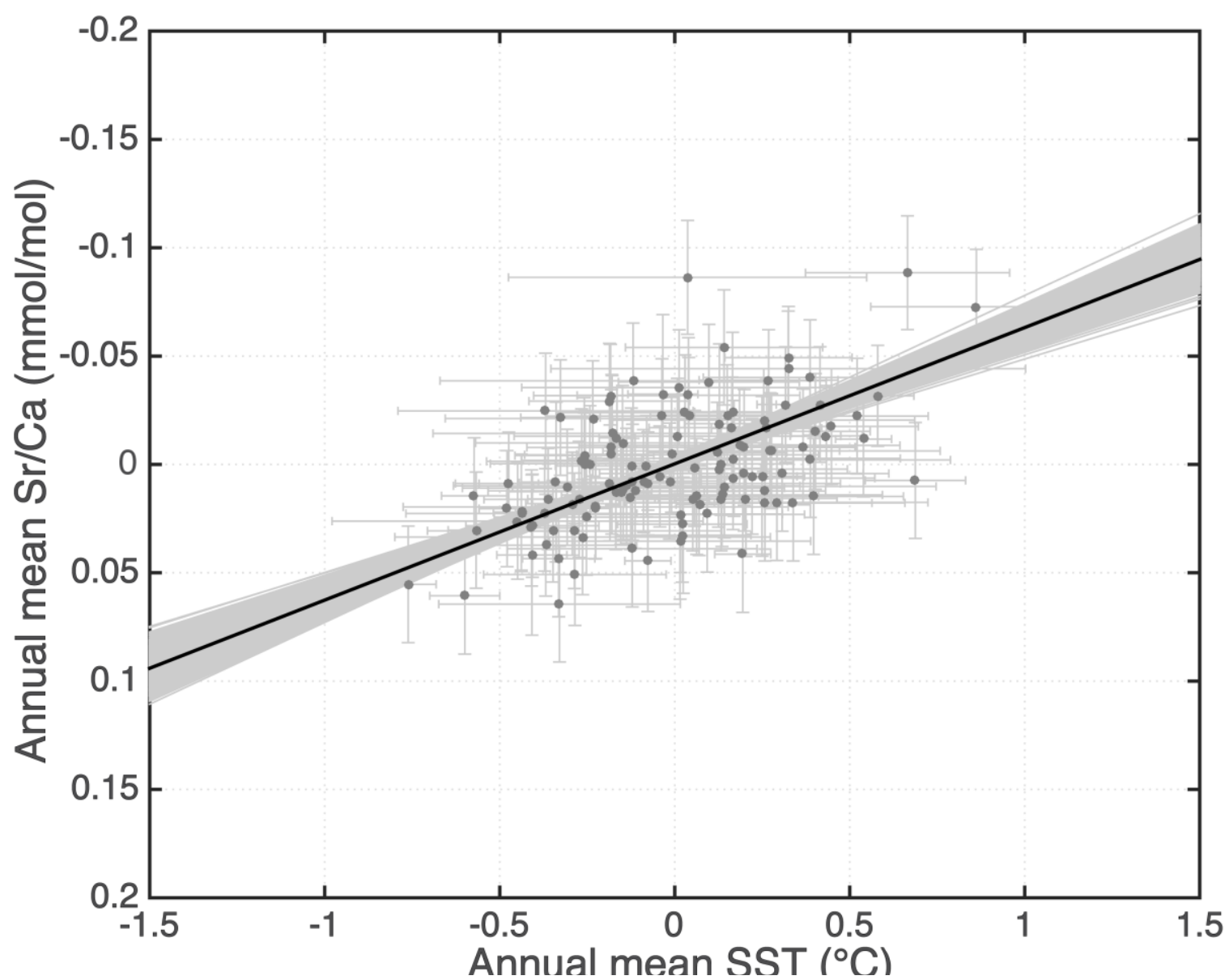

411 Figure 9. Regression line determined by applying the BWLS technique to annual $\mathrm{Sr} / \mathrm{Ca}$

412 anomalies and annual ERSST anomalies from Anegada, Guadeloupe, and Bonaire.

415 provides regression-independent data to assess reconstruction errors. For each iteration

416 of the regression, the derived $\mathrm{Sr} / \mathrm{Ca}-\mathrm{SST}$ slope is applied to these regression-independent

417 data and the calculated SSTs compared to instrumental SST. For the 3-coral Anegada

418 regressions $95 \%$ of the monthly SST reconstructions are within $\pm 1.2^{\circ} \mathrm{C}$ of the

419 instrumental temperature, providing a 95\% confidence level that can be assigned to a

420 reconstructed temperature. Similar analysis of the Anegada monthly anomaly and annual

421 data results in confidence intervals of $\pm 1.0^{\circ} \mathrm{C}$ and $0.8^{\circ} \mathrm{C}$, respectively. $95 \%$ confidence 
422 intervals for reconstructed temperatures using all 5 corals are $\pm 1.3, \pm 1.0$, and $\pm 0.7{ }^{\circ} \mathrm{C}$ for

423 monthly, monthly anomaly and annual data respectively.

\section{Discussion}

426 4.1 Mean Differences

The corals in this study have different mean $\mathrm{Sr} / \mathrm{Ca}$ ratios that cannot be explained

428 by differences in mean temperature at the time of coral growth according to the gridded

429 temperature data. Mean differences between cores in this situation have multiple

430 potential causes including: 1) the corals may have grown on different parts of the reef

431 that may have had different temperatures (such as at different depths), 2) they may have

432 grown on different parts of the reef with different mean seawater $\mathrm{Sr} / \mathrm{Ca}$, and 3) biological

433 factors may have influenced the mean Sr/Ca. Although many studies have demonstrated

434 the consistency of $\mathrm{Sr} / \mathrm{Ca}$ ratios among Porites lutea and Siderastrea siderastrea coral

435 colonies [DeLong et al., 2007; DeLong et al., 2011; DeLong et al., 2014; Stephans et al.,

436 2004], there is some evidence that different coral colonies growing near each other can

437 have colony-specific offsets in mean Sr/Ca ratios [DeLong et. al., 2011; de Villiers et al., 438 1994].

439 No significant relationship was found between annual $\mathrm{Sr} / \mathrm{Ca}$ and growth rate in 440 each coral colony, though it is possible that the mean shift of the growth rates in these 441 three modern corals are responsible for the mean shift of the $\mathrm{Sr} / \mathrm{Ca}$ ratios (Table 7). The

442 relatively high $\mathrm{Sr} / \mathrm{Ca}$ ratios and relatively low growth rates in coral 13AN18, compared to 443 the other modern corals, is consistent with previous studies that suggest slower growing 
444 Diploria colonies have higher Sr/Ca ratios [Goodkin et al., 2005]. Without benefit of an

445 array of thermistors monitoring SST variability on the reef and a water sampling program

446 to ensure no seawater Sr/Ca changes could be impacting our site, we conclude that the

447 cause of mean shifts in coral colony $\mathrm{Sr} / \mathrm{Ca}$ ratios is ambiguous at this time. Uncertainty

448 in mean values prohibits interpretation of mean $D$. strigosa $\mathrm{Sr} / \mathrm{Ca}$ in terms of mean

449 climate, but does not necessarily impact interannual or seasonal variations.

452 Table 7. Annual mean growth rates and Sr/Ca ratios with $1 \sigma$ standard error in modern corals.

\begin{tabular}{llll}
\hline & AN17 & AN18 & AN19 \\
$\begin{array}{l}\text { Number of years } \\
\text { Mean Sr/Ca (mmol/mol) }\end{array}$ & 18 & 28 & 10 \\
$\begin{array}{l}\text { Mean Extension rate } \\
\text { (mm/year) }\end{array}$ & $6.9 \pm \pm 0.4$ & $9.129 \pm 0.003$ & $8.953 \pm 0.005$ \\
$\begin{array}{l}\text { Annual Sr/Ca-Extension } \\
\text { correlation } \\
\text { p-value }\end{array}$ & 0.16 & $5.6 \pm 0.2$ & $6.2 \pm 0.4$ \\
\hline
\end{tabular}

453

454

455

456

457

458

459

460

461 statistically different from each other, but are mostly within a relatively narrow range of

462 slopes compared to the range of $\mathrm{Sr} / \mathrm{Ca}-\mathrm{SST}$ slopes reported in the literature for a variety

463 of species [Chen et al., 2013; Corrège, 2006; DeLong et al., 2011; Sadler et al., 2014].

464 The fact that we obtained significantly different results with the same data indicates that a 465 portion of the range of Sr/Ca-SST slopes in the literature can be attributed to different 
466 regression techniques alone. Our analysis demonstrates that the assumptions about data

467 uncertainty inherent in each regression technique strongly impacts the resulting

468 regression slope obtained from any given data set. When the implicit assumptions about

469 data uncertainty do not reflect reality, the resulting slopes lead to biased estimations of

470 SST [Solow and Huppert, 2004].

$471 \quad$ Assessing temperature uncertainty has historically been very difficult for coral

472 calibration studies because our study sites are often remote and without long-term local

473 temperature monitoring. The recent release of ERSST v3b and HadSST gridded SST

474 data products which include gridbox-specific estimates of the mean monthly temperature

475 uncertainty provides at least some quantifiable uncertainty estimates when using gridded

476 SST data. This does not solve the fundamental issue of whether to calibrate with local

477 rather than gridded SST, but we point out that the coral is fundamentally experiencing

478 local SST, so calibrations using gridded data (present study included) will inherently

479 have some variance in $\mathrm{Sr} / \mathrm{Ca}$ that is due to local SST and is not explainable with the

480 gridded SST data. Consequently, estimates of SST reconstruction error will be larger

481 than they might have been if accurate and precise local SST data were available.

482 Besides the choice of SST data to use, calibration studies need to choose a

483 regression technique. We recommend future calibration studies use the unbiased WLS

484 regression technique with either estimates of gridded SST uncertainty now available, or

485 estimates of local SST error based on an understanding of the local SST data and the

486 local coastal SST dynamics. The WLS calibration technique accounts for unequal errors

487 in both the dependent and independent variables and thus provides the best estimation of

488 the underlying Sr/Ca-SST relationship. MATLAB code available from [Thirumalai et 
al., 2011] makes implementation easily accessible to most researchers. Standardizing the

490 methods used for calibration may clarify if genus- or species-specific universal

491 calibrations as proposed by Weber [1973] are realistic or if ad-hoc calibrations at every

492 study site are necessary.

4944.3 Towards a universal Diploria strigosa calibration

495 Accepting as a premise Weber's [1973] assertion that a taxon-specific ideal

496 calibration exists, we combine Sr/Ca data from our study site with existing published

$497 \mathrm{Sr} / \mathrm{Ca}$ from this species to quantify a best-possible $\mathrm{Sr} / \mathrm{Ca}-\mathrm{SST}$ relationship for $D$. strigosa:

$498-0.0463( \pm 0.0004) \mathrm{mmol} / \mathrm{mol} /{ }^{\circ} \mathrm{C}$ for mean-centered data (Figure 6), $-0.0590( \pm 0.0012)$

$499 \mathrm{mmol} / \mathrm{mol} /{ }^{\circ} \mathrm{C}$ for monthly anomalies and $-0.063( \pm 0.004)$ for annual data. This result is

500 well within the range of results for the three Anegada corals. The five-coral result is

501 slightly steeper than the individual coral calibrations from Guadeloupe $(0.042$

$\left.502 \mathrm{mmol} / \mathrm{mol} /{ }^{\circ} \mathrm{C}\right)\left[\right.$ Hetzinger et al., 2006] and Bonaire $\left(0.034 \mathrm{mmol} / \mathrm{mol} /{ }^{\circ} \mathrm{C}\right)[$ Giry et al.,

503 2012]. The use of five individual coral heads from three sites in the regression minimizes

504 the potential influence of differences between coral colonies to get a result that is more

505 appropriately applicable to an individual chosen from the population at random e.g., a

506 sub-fossil coral washed ashore. Future paleoclimate studies can use this calibration with

507 confidence that it is not a result skewed by the vagaries of a single colony or a single

508 study site.

509 Our combined regression is done with mean-centered, monthly anomaly, and

510 mean annual anomaly data separately to give other researchers the ability to choose

511 which they want to use because each has their benefits and drawbacks. All of the data 
512 (monthly, monthly anomalies, and annual data) were set to zero mean before regression

513 with temperature data to minimize any non-temperature related mean differences that

514 might be due to differences in average growth rate, un-identified biological factors, or

515 interlaboratory calibration issues. The mean-centered monthly data effectively calibrates

516 the seasonal cycles of SST and Sr/Ca because the seasonal cycle dominates the variance

517 of both records. Given the potential for within-year skeletal thickening and its potential

518 impact on the apparent Sr/Ca-SST relationship [Gagan et al., 2012], calibrations that

519 include the seasonal cycle are most robust when applied to studies investigating the

520 seasonal cycles of SST.

521 Ideally, calibrating with anomaly data is robust for investigating interannual and

522 longer changes in SST. However, Sr/Ca-SST regression slopes obtained from anomaly

523 data are not well characterized because of the low signal to noise ratios inherent in SST

524 and coral Sr/Ca data and the sensitivity of the resulting regression slopes to

525 methodological assumptions about data uncertainty. Delong et al. [2014] point out that

526 most of the scatter in a monthly anomaly Sr/Ca-SST regression is due to small sub-annual

527 age-model errors, making monthly anomaly regressions inherently noisy and unreliable.

528 Instead, annual average data provide the basis for our long-timescale calibration.

529 Interestingly, with the Anegada corals, we get effectively the same Sr/Ca-SST

530 relationship from the mean annual data as we do calibrating the seasonal cycle, implying

531 that perhaps Diploria strigosa colonies do not thicken their skeletons throughout the

532 tissue layer as Gagan et al. [2012] demonstrated for Porites. However, the five-coral

533 multi-site calibration shows the expected increase in slope for the annual data regression,

534 indicating that a more likely explanation for the Anegada-only results is that the smaller 
535 number of data points and low signal to noise ratio make the true skeletal Sr/Ca-SST

536 relationship difficult to precisely characterize.

537 Annual data have one major drawback similar to monthly anomalies: namely that

538 there is less variance in SST, so you are calibrating over a very narrow range. The best

539 thing to do to remedy this is a regional mean calibration with multiple corals, such as in

540 the original Weber [1973] paper and more recently in Delong et al. [2010]. However we

541 could not conduct a similar regional mean calibration because the existing data for this

542 species all come from reefs with the same long-term mean temperature. Additionally, the

$543 \mathrm{Sr} / \mathrm{Ca}$ data were produced in different labs that have not cross-calibrated and thus the data

544 may have undetected instrument calibration issues [Hawthorn et al., 2013].

\section{Conclusions}

547 In this study, we assess four different calibration regression methods and conclude

548 that the standard practice of ordinary least squares regression should be replaced with

549 weighted least squares regression given the typical distribution of error between the

550 geochemistry and instrumental temperature data. Our calibration using D. strigosa from

551 Anegada, British Virgin Islands is similar to previous calibrations using this species from

552 other sites, suggesting that $\mathrm{Sr} / \mathrm{Ca}$-SST calibrations from our study are widely applicable

553 to this species. We have produced a three-site, five-colony calibration that can be utilized

554 for future paleoclimate reconstructions with $D$. strigosa. In addition, our results indicate

555 that whereas significant mean differences among individuals at the study site were 
556 observed, seasonal and interannual temperature variability can still be distinguished using

557 the skeletal geochemistry of D. strigosa.

559 Acknowledgements: We acknowledge two anonymous reviewers and associate editor

560 Thierry Corrége for helpful comments that significantly improved this paper. Grants

561 from the National Science Foundation to KHK (OCE-1203947) and to Maryland Sea

562 Grant (OCE-1262374) for the Maryland Sea Grant Research Experiences for

563 Undergraduates program supported this work. We gratefully thank Dr. Lee Cooper and

564 Dr. Johan Schijf, for their comments and suggestions on an early version of the

565 manuscript. We are indebted to Chuan-Zhou Shen and Hai-Long Sun for their technical

566 support on Uranium-series dates and to Bob Halley, Edgardo Quiñones and Zamara

567 Fuentes for their significant assistance with fieldwork. This is contribution No. 5046 of

568 the University of Maryland Center for Environmental Science.

\section{References}

Budd, A. F., H. Fukami, N. D. Smith, and N. Knowlton (2012), Taxonomic classification of the reef coral family Mussidae (Cnidaria: Anthozoa: Scleractinia), Zoological Journal of the Linnean Society, 166(3), 465-529.

Cardinal, D., B. Hamelin, E. Bard, and J. Pätzold (2001), Sr/Ca, U/Ca and $\delta^{18} \mathrm{O}$ records in recent massive corals from Bermuda: relationships with sea surface temperature, Chemical Geology, 176(1-4), 213-233.

Cavalli-Sforza, L. L., and A. W. Edwards (1967), Phylogenetic Analysis Models and Estimation Procedures, American Journal of Human Genetics, 19(3 Part 1), 233.

Chen, T., K. Yu, and T. Chen (2013), Sr/Ca-sea surface temperature calibration in the coral Porites lutea from subtropical northern South China Sea, Palaeogeography, Palaeoclimatology, Palaeoecology, 392, 98-104.

Clarke, M. R. B. (1980), The reduced major axis of a bivariate sample, Biometrika, 67(2), 441-446. 
Cobb, K. M., C. D. Charles, H. Cheng, and R. L. Edwards (2003), El Nino/Southern Oscillation and tropical Pacific climate during the last millennium, Nature, 424(6946), 271-276.

Cohen, A. L., and S. R. Thorrold (2007), Recovery of temperature records from slowgrowing corals by fine scale sampling of skeletons, Geophysical Research Letters, 34(17).

Cohen, A. L., S. R. Smith, M. S. McCartney, and J. van Etten (2004), How brain corals record climate: an integration of skeletal structure, growth and chemistry of Diploria labyrinthiformis from Bermuda, Marine Ecology Progress Series, 271, 147-158.

Corrège, T. (2006), Sea surface temperature and salinity reconstruction from coral geochemical tracers, Palaeogeography, Palaeoclimatology, Palaeoecology, 232(2-4), 408-428.

Crowley, T. J., T. M. Quinn, and W. T. Hyde (1999), Validation of coral temperature calibrations, Paleoceanography, 14(5), 605-615.

de Villiers, S., G. T. Shen, and B. K. Nelson (1994), The Sr/Ca-temperature relationship in coralline aragonite: Influence of variability in $(\mathrm{Sr} / \mathrm{Ca})$ seawater and skeletal growth parameters, Geochimica et Cosmochimica Acta, 58(1), 197-208.

DeLong, K. L., J. A. Flannery, C. R. Maupin, R. Z. Poore, and T. M. Quinn (2011), A coral $\mathrm{Sr} / \mathrm{Ca}$ calibration and replication study of two massive corals from the Gulf of Mexico, Palaeogeography, Palaeoclimatology, Palaeoecology, 307(1-4), 117128.

DeLong, K. L., T. M. Quinn, and F. W. Taylor (2007), Reconstructing twentieth-century sea surface temperature variability in the southwest Pacific: A replication study using multiple coral $\mathrm{Sr} / \mathrm{Ca}$ records from New Caledonia, Paleoceanography, 22(4), PA4212.

DeLong, K. L., T. M. Quinn, C.-C. Shen, and K. Lin (2010), A snapshot of climate variability at Tahiti at $9.5 \mathrm{ka}$ using a fossil coral from IODP Expedition 310, Geochemistry, Geophysics, Geosystems, 11(6), Q06005.

DeLong, K. L., J. A. Flannery, R. Z. Poore, T. M. Quinn, C. R. Maupin, K. Lin, and C.-C. Shen (2014), A reconstruction of sea surface temperature variability in the southeastern Gulf of Mexico from 1734 to 2008 C.E. using cross-dated $\mathrm{Sr} / \mathrm{Ca}$ records from the coral Siderastrea siderea, Paleoceanography, 29(5), 403-422.

Draschba, S., J. Pätzold, and G. Wefer (2000), North Atlantic climate variability since $\mathrm{AD} 1350$ recorded in $\delta^{18} \mathrm{O}$ and skeletal density of Bermuda corals, International Journal of Earth Sciences, 88(4), 733-741.

Efron, B. and R. Tibshirani (1986), Bootstrap methods for standard errors, confidence intervals and other measures of statistical accuracy, Statistical Science, 1(1), 5475.

Fitch, W. M., and E. Margoliash (1967), Construction of phylogenetic trees, Science, 155(760), 279-284.

Gagan, M. K., G. B. Dunbar, and A. Suzuki (2012), The effect of skeletal mass accumulation in Porites on coral $\mathrm{Sr} / \mathrm{Ca}$ and $\delta^{1}{ }^{8} \mathrm{O}$ paleothermometry, Paleoceanography, 27(1), PA1203. 
Giry, C., T. Felis, M. Kölling, and S. Scheffers (2010), Geochemistry and skeletal structure of Diploria strigosa, implications for coral-based climate reconstruction, Palaeogeography, Palaeoclimatology, Palaeoecology, 298(3-4), 378-387.

Giry, C., T. Felis, M. Kölling, D. Scholz, W. Wei, G. Lohmann, and S. Scheffers (2012), Mid-to late Holocene changes in tropical Atlantic temperature seasonality and interannual to multidecadal variability documented in southern Caribbean corals, Earth and Planetary Science Letters, 331, 187-200.

Goodkin, N. F., K. A. Hughen, and A. L. Cohen (2007), A multicoral calibration method to approximate a universal equation relating $\mathrm{Sr} / \mathrm{Ca}$ and growth rate to sea surface temperature, Paleoceanography, 22(1), PA1214.

Goodkin, N. F., K. A. Hughen, A. L. Cohen, and S. R. Smith (2005), Record of Little Ice Age sea surface temperatures at Bermuda using a growth-dependent calibration of coral Sr/Ca, Paleoceanography, 20(4), PA4016.

Hathorne, E. C., et al. (2013), Interlaboratory study for coral $\mathrm{Sr} / \mathrm{Ca}$ and other element/Ca ratio measurements, Geochemistry, Geophysics, Geosystems, 14(9), 3730-3750.

Hetzinger, S., M. Pfeiffer, W.-C. Dullo, D. Garbe-Schönberg, and J. Halfar (2010), Rapid 20th century warming in the Caribbean and impact of remote forcing on climate in the northern tropical Atlantic as recorded in a Guadeloupe coral, Palaeogeography, Palaeoclimatology, Palaeoecology, 296(1-2), 111-124.

Hetzinger, S., M. Pfeiffer, W.-C. Dullo, E. Ruprecht, and D. Garbe-Schönberg (2006), $\mathrm{Sr} / \mathrm{Ca}$ and $\delta^{18} \mathrm{O}$ in a fast-growing Diploria strigosa coral: Evaluation of a new climate archive for the tropical Atlantic, Geochemistry, Geophysics, Geosystems, 7(10), Q10002.

Kilbourne, K. H., T. M. Quinn, R. Webb, T. Guilderson, J. Nyberg, and A. Winter (2008), Paleoclimate proxy perspective on Caribbean climate since the year 1751: Evidence of cooler temperatures and multidecadal variability, Paleoceanography, 23(3), PA3220.

Kuhnert, H., J. Pätzold, B. Schnetger, and G. Wefer (2002), Sea-surface temperature variability in the 16th century at Bermuda inferred from coral records1, Palaeogeography, Palaeoclimatology, Palaeoecology, 179(3-4), 159-171.

McGregor, H. V., and M. K. Gagan (2003), Diagenesis and geochemistry of Porites corals from Papua New Guinea: Implications for paleoclimate reconstruction, Geochimica et Cosmochimica Acta, 67(12), 2147-2156.

Nurhati, I. S., K. M. Cobb, C. D. Charles, and R. B. Dunbar (2009), Late 20th century warming and freshening in the central tropical Pacific, Geophysical Research Letters, 36(21), L21606.

Paillard, D., L. Labeyrie, and P. Yiou (1996), Macintosh Program performs time-series analysis, Eos, Transactions American Geophysical Union, 77(39), 379-379.

Pfeiffer, M., W.-C. Dullo, J. Zinke, and D. Garbe-Schönberg (2008), Three monthly coral $\mathrm{Sr} / \mathrm{Ca}$ records from the Chagos Archipelago covering the period of 1950-1995

A.D.: reproducibility and implications for quantitative reconstructions of sea surface temperature variations, International Journal of Earth Sciences, 98(1), 5366.

Quinn, T. M., and D. E. Sampson (2002), A multiproxy approach to reconstructing sea surface conditions using coral skeleton geochemistry, Paleoceanography, 17(4), 1062. 
674

675

676

677

678

679

680

681

682

683

684

685

686

687

688

689

690

691

692

693

694

695

696

697

698

699

700

701

702

703

704

705

706

707

708

709

710

711

712

713

714

715

716

717

718

Reynolds, R. W., T. M. Smith, C. Liu, D. B. Chelton, K. S. Casey, and M. G. Schlax (2007), Daily high-resolution-blended analyses for sea surface temperature, Journal of Climate, 20(22), 5473-5496.

Sadler, J., G. E. Webb, L. D. Nothdurft, and B. Dechnik (2014), Geochemistry-based coral palaeoclimate studies and the potential of 'non-traditional' (non-massive Porites) corals: Recent developments and future progression, Earth-Science Reviews, 139, 291-316.

Saenger, C., A. L. Cohen, D. W. Oppo, and D. Hubbard (2008), Interpreting sea surface temperature from strontium/calcium ratios in Montastrea corals: Link with growth rate and implications for proxy reconstructions, Paleoceanography, 23(3), PA3102.

Schrag, D. P. (1999), Rapid analysis of high-precision $\mathrm{Sr} / \mathrm{Ca}$ ratios in corals and other marine carbonates, Paleoceanography, 14(2), 97-102.

Shen, C.-C., H. Cheng, R. L. Edwards, S. B. Moran, H. N. Edmonds, J. A. Hoff, and R. B. Thomas (2003), Measurement of attogram quantities of 231Pa in dissolved and particulate fractions of seawater by isotope dilution thermal ionization mass spectroscopy, Analytical Chemistry, 75(5), 1075-1079.

Shen, C.-C., T. Lee, C.-Y. Chen, C.-H. Wang, C.-F. Dai, and L.-A. Li (1996), The calibration of $D[\mathrm{Sr} / \mathrm{Ca}]$ versus sea surface temperature relationship for Porites corals, Geochimica et Cosmochimica Acta, 60(20), 3849-3858.

Shen, C.-C., C.-C. Wu, H. Cheng, R. Lawrence Edwards, Y.-T. Hsieh, S. Gallet, C.-C. Chang, T.-Y. Li, D. D. Lam, and A. Kano (2012), High-precision and highresolution carbonate ${ }^{230} \mathrm{Th}$ dating by MC-ICP-MS with SEM protocols, Geochimica et Cosmochimica Acta, 99, 71-86.

Shen, C.-C., et al. (2008), Variation of initial 230Th/232Th and limits of high precision U-Th dating of shallow-water corals, Geochimica et Cosmochimica Acta, 72(17), 4201-4223.

Smith, R. J. (2009), Use and misuse of the reduced major axis for line - fitting, American Journal of Physical Anthropology, 140(3), 476-486.

Smith, T. M., and R. W. Reynolds (2004), Improved extended reconstruction of SST (1854-1997), Journal of Climate, 17(12), 2466-2477.

Smith, T. M., R. W. Reynolds, T. C. Peterson, and J. Lawrimore (2008), Improvements to NOAA's historical merged land-ocean surface temperature analysis (1880-2006), Journal of Climate, 21(10), 2283-2296.

Smith, J. M., T. M. Quinn, K. P. Helmle, and R. B. Halley (2006), Reproducibility of geochemical and climatic signals in the Atlantic coral Montastraea faveolata, Paleoceanography, 21(1), PA1010.

Solow, A. R., and A. Huppert (2004), A potential bias in coral reconstruction of sea surface temperature, Geophysical Research Letters, 31(6), L06308.

Stephans, C. L., T. M. Quinn, F. W. Taylor, and T. Corrège (2004), Assessing the reproducibility of coral - based climate records, Geophysical Research Letters, 31(18).

Swart, P. K., H. Elderfield, and M. J. Greaves (2002), A high-resolution calibration of $\mathrm{Sr} / \mathrm{Ca}$ thermometry using the Caribbean coral Montastraea annularis, Geochemistry, Geophysics, Geosystems, 3(11), 8402. 
Thirumalai, K., A. Singh, and R. Ramesh (2011), A MATLAB ${ }^{\text {TM }}$ code to perform weighted linear regression with (correlated or uncorrelated) errors in bivariate data, Journal of the Geological Society of India, 77(4), 377-380.

Watanabe, T., A. Winter, and T. Oba (2001), Seasonal changes in sea surface temperature and salinity during the Little Ice Age in the Caribbean Sea deduced from $\mathrm{Mg} / \mathrm{Ca}$ and ${ }^{18} \mathrm{O} /{ }^{16} \mathrm{O}$ ratios in corals, Marine Geology, 173(1-4), 21-35.

Watanabe, T., A. Winter, T. Oba, R. Anzai, and H. Ishioroshi (2002), Evaluation of the fidelity of isotope records as an environmental proxy in the coral Montastraea, Coral Reefs, 21(2), 169-178.

Weber, J. N. (1973), Incorporation of strontium into reef coral skeletal carbonate, Geochimica et Cosmochimica Acta, 37(9), 2173-2190.

York, D., N. M. Evensen, M. L. Martınez, and J. D. B. Delgado (2004), Unified equations for the slope, intercept, and standard errors of the best straight line, American Journal of Physics, 72(3), 367-375. 